\title{
The Effect of Preventive Trimming on Weight Bearing and Force Balance on the Claws of Dairy Cattle
}

\author{
P. P. J. van der Tol, ${ }^{1}$ S.S. van der Beek, ${ }^{1}$ J. H. M. Metz, ${ }^{4}$ E. N. Noordhuizen-Stassen, ${ }^{2}$ \\ W. Back, ${ }^{3}$ C. R. Braam, ${ }^{5}$ and W. A. Weijs ${ }^{1}$ \\ ${ }^{1}$ Department of Veterinary Anatomy, ${ }^{2}$ Department of Farm Animal Health; \\ and ${ }^{3}$ Department of Equine Sciences, Faculty of Veterinary Medicine, \\ Utrecht University, 3508 TD Utrecht, The Netherlands \\ ${ }^{4}$ Institute of Agricultural and Environmental Engineering, \\ 6700 AA Wageningen, The Netherlands \\ ${ }^{5}$ Faculty of Civil Engineering and Geosciences, \\ University of Technology, 2600 GA Delft, The Netherlands
}

\section{ABSTRACT}

Claw disorders and lameness in dairy cattle are an increasing problem of the modern dairy industry. To prevent claw disorders from evolving from the subclinical to the clinical stage, trimming is the management practice most routinely applied. The goal of preventive trimming (Toussaint-Raven method) is to promote natural loading by increasing the weight-bearing contact area of the claws and improving the balance between the medial and lateral claw. The biomechanical effect of preventive claw trimming was investigated with the aid of pressure distribution and ground reaction force recordings of the standing cow sampled simultaneously at $250 \mathrm{~Hz}$.

It appeared that preventive trimming of the hind limbs $(\mathrm{n}=10)$ brought the claws slightly more in balance. Before trimming, $80 \%$ of the total force is taken up by the lateral claw and $20 \%$ by the medial claw. After trimming, this becomes 70 to $30 \%$, respectively. Thereby, a significant increase in the weight-bearing contact area from 27.5 to $40.0 \mathrm{~cm}^{2}$ was achieved, resulting in a significant decrease in average pressure. However, the claws remained subjected to unaltered, high maximum pressures after trimming.

The suggestion was made that the main focus of claw trimming should not be force balance; instead, a reduction of local maximum pressures at the contact area should be targeted in such a way that the strongest parts of the claw capsule (i.e., the wall) will be subjected to the highest pressures.

(Key words: claw disorder, lameness, biomechanics, trimming)

Received July 18, 2003.

Accepted February 19, 2004.

Corresponding author: P. P. J. (Rik) van der Tol; e-mail: Rik. vanderTol@wur.nl.
Abbreviation key: FB = force balance, $\mathbf{G R F}=$ ground reaction force.

\section{INTRODUCTION}

In the past, claw disorders and lameness in dairy cattle have been an increasing problem of the modern dairy industry. Such disorders and lameness have often been associated with housing characteristics (Russel et al., 1982; Esslemont and Spincer, 1993; Clarkson et al., 1996; Somers et al., 2003). In addition to an economic impact (Enting et al., 1997; Borsberry et al., 1999), these disorders compromised animal welfare (Whay et al., 1997). Van der Tol et al. (2003) showed that pressures exerted to the claw reach relatively high values during locomotion on a flat, hard surface and suggested that resulting horn damage is a probable cause of claw disorders.

Most claw disorders are noticed when the locomotion of the animal is strongly affected, as in lameness. However, a cow might already suffer from a claw disorder before locomotion is visually disturbed. During the housing period, subclinical claw disorders affect up to $70 \%$ of dairy cattle in the western European husbandry (Hedges et al., 2001; Somers et al., 2003).

To prevent the evolution of claw disorders from evolving from the subclinical to the clinical stage, the management practice applied routinely is trimming. Described briefly, the goal of trimming is to promote natural loading of the claws by reshaping the claw capsule in three steps: 1) the toe length of the medial claw is cut to $7.5 \mathrm{~cm}$, and the sole is made flat, whereby the wall and sole are paired to the same level; 2) the contact areas of the lateral and medial claw are adjusted to the same height; and 3) the axial walls are concavely reshaped (Toussaint-Raven et al., 1985). Current practice in the modern dairy industry is that trimming should be initiated 2 to 3 times a year to provide the cow with good balanced feet (Manske et al., 2002), and 
a large contact area is the best option. It has been shown empirically that both subclinical and clinical claw disorders occurred less frequently when the feet were trimmed routinely 2 to 3 times a year and that the occurring lameness cases were less severe (Manson and Leaver, 1989; Manske et al., 2002).

Toussaint-Raven was the first who biomechanically showed a positive effect of claw trimming on the force balance (FB) while standing (1973). However, the data of Toussaint-Raven's study were obtained from cows that were, according to him, "sensitive" on their feet and probably in need of curative trimming. For the past 3 decades, the beneficial effect of curative trimming was rationalized, making preventative trimming valid (Toussaint-Raven et al., 1985; Vermunt and Greenough, 1995; Shearer and Van Amstel, 2001). Furthermore, it was assumed without experimental proof that trimming decreased the average pressure, maximum pressure, or both (Toussaint-Raven, 1985; Gonzalez Sagues, 2002; Van Amstel, 2002). Although on theoretical and empirical grounds it can be surmised that preventive trimming has a positive effect on claw health, no insight was gained into the cause of this effect, and the direct biomechanical consequences of routine preventive trimming are unclear.

Therefore, an experiment was conducted to test the biomechanical effect of routine preventive trimming. One of the popular trimming methods was described by Toussaint-Raven et al. (1985). That reference provides guidelines to prevent over-trimming and is applied by $83 \%$ of western European trimmers (O'Callaghan et al., 2001). The hind feet were preventively trimmed according to this "Dutch" method. The hypotheses tested included the following: 1) that trimming promotes a more even distribution of the vertical force over both claws of one limb and 2) that trimming reduces the average and maximum pressures to which the horn of the claw at the contact area is subjected.

\section{MATERIALS AND METHODS}

At the end of the grazing period, 5 dairy cows (Holstein-Friesians; age $=4.7 \pm 1.0 \mathrm{yr}$; weight $=704 \pm 136$ $\mathrm{kg}$ ) with no visual signs of claw disorders or lameness were subjected to the experiment, which had been approved by the Animal Experimentation Committee of the Faculty of Veterinary Medicine, Utrecht University. The animals came from a herd kept at the experimental farm 'De Tolakker' of the Faculty of Veterinary Medicine, Utrecht University. During the day, the cows were at pasture; at night, they were kept in a loose cubicle house with slatted concrete floors. The walking areas were cleaned automatically every $20 \mathrm{~min}$ via a manure scraper. The cows were considered locomotory healthy and typical for the Dutch, high-productive dairy cows (average production $= \pm 8000 \mathrm{~kg}$ per lactation).

The pressure-force measuring system consisted of a pressure distribution plate and a force plate sampled simultaneously $(250 \mathrm{~Hz})$. The pressure distribution plate (footscan scientific version; RsScan International, Olen, Belgium) has a $976-\mathrm{mm} \times 325-\mathrm{mm}$ measuring surface containing 8192 conductive pressure-sensitive polymer sensors. These sensors measured vertical force only. Because the size of the sensors is known ( 0.39 $\mathrm{cm}^{2}$ ), the pressures are determined automatically. This plate was embedded in an aluminium plate, which was solidly assembled on the force plate (Type Z4852/c; 600 $\mathrm{mm} \times 900 \mathrm{~mm}$; Kistler Corp, Winterthur, Switzerland). The force plate measured the vertical, longitudinal, and transverse components of the ground reaction force (GRF). The top surface of the assembly was placed level with a concrete pathway. The pathway and measuring apparatus were covered with a level 5- to 6-mm thick rubber mat, providing a level surface for the 4 feet and enough frictional force (i.e., the horizontal component of the GRF) to prevent possible minor postural adjustments caused by a slippery floor.

Each trial had a duration of $4 \mathrm{~s}$. Per measurement, the footscan collected 8192 (sensors) $\times 1000$ (samples) data points. The pressures were linearly distributed and color-coded over 256 available colors between the minimum pressure (blue) and the maximum pressure (red). In this experiment, the footscan pressure plate uses the output (vertical GRF) of the Kistler Force plate directly for calibration. Therefore, for each sample point in time, the measurements of the individual sensors were multiplied by a specific calibration factor $\mathrm{C}$, equaling the vertical force registered by the force plate, divided by the sum of the vertical pressures applied to all individual sensors of the pressure plate at that moment.

\section{Experimental Procedures}

Prior to the measurements, the feet were cleaned. The cows were positioned on the plate with one foot. After they were standing still in a stable position and supported by all 4 feet, a measurement was performed. A previous experiment showed that the pressure recordings were stable during such measurements (Van der Tol et al., 2002). After a measurement, the cow was led away from the plate and positioned again until 5 measurements for all 4 limbs had been recorded.

After the first series of measurements, the hind claws of the cows were routinely trimmed according the 'Dutch trimming method' (Toussaint-Raven et al., 1985) by an experienced claw trimmer. During the trimmings, the claws were examined for the presence of claw disorders: interdigital dermatitis, digital dermatitis, sole 
hemorrhages, sole ulcers, and white line lesions as described in detail by Somers et al. (2003). To allow the cows to adapt to their trimmed claws, a second series of measurements took place 2 wk after trimming, according the same protocol.

Parameters. Consider $\mathrm{F}_{\mathrm{i}}$ an above-threshold vertical force applied to sensor i of the pressure plate corrected by calibration factor $\mathrm{C}$ and $\mathrm{A}_{\mathrm{s}}$ the surface of each sensor. The following parameters were determined for each measurement:

- The total vertical GRF $\left(\mathrm{Fv}_{\mathrm{t}}\right)$ exerted to the lateral $\left(\mathrm{Fv}_{\mathrm{l}}\right)$ and medial claw $\left(\mathrm{Fv}_{\mathrm{m}}\right)$ in Newton $(\mathrm{N})$ :

$\mathrm{Fv}_{\mathrm{l}}=\Sigma \mathrm{F}_{\mathrm{i}}$ of the lateral claw;

$\mathrm{Fv}_{\mathrm{m}}=\Sigma \mathrm{F}_{\mathrm{i}}$ of the medial claw.

- $\mathrm{Fv}_{\mathrm{t}}=\mathrm{Fv}_{\mathrm{l}}+\mathrm{Fv}_{\mathrm{m}}$ of the total foot.

- The contact area of the foot with the floor $\left(\mathrm{A}_{\mathrm{f}}\right.$ in $\mathrm{cm}^{2}$ ):

$$
\mathrm{A}_{\mathrm{f}}=\Sigma \mathrm{n}\left(\mathrm{F}_{\mathrm{i}}>15 \mathrm{~N}\right) \times \mathrm{A}_{\mathrm{s}} ;
$$

$\mathrm{n}\left(\mathrm{F}_{\mathrm{i}}>15 \mathrm{~N}\right)=$ number of sensors with a force $>15$ $\mathrm{N}$.

To account for the partial contribution to the contact area of sensors located at the contour of the contact area, the threshold level was set to $15 \mathrm{~N}$ per sensor.

- The average pressure per foot $\left(\mathrm{P}_{\mathrm{av}}\right)$ in $\mathrm{N} / \mathrm{cm}^{2}$ : $\mathrm{P}_{\mathrm{av}}=\mathrm{Fv}_{\mathrm{t}} / \mathrm{A}_{\mathrm{f}}$.

- The maximum pressure per foot $\left(\mathrm{P}_{\max }\right)$ in $\mathrm{N} / \mathrm{cm}^{2}$ : $\mathrm{P}_{\max }=\mathrm{F}_{\mathrm{I}(\max )} / \mathrm{A}_{\mathrm{s}}$;

$\mathrm{F}_{\mathrm{i}(\max )}=$ highest $\mathrm{F}_{\mathrm{i}}$ occurring at the contact area of the entire foot.

\section{Statistical Analysis}

The average value of the 5 measurements taken per limb of each cow was used for the statistics. To analyze a change in the FB between lateral and medial claws, the log was taken of the ratio $\left(\mathrm{Fv}_{\mathrm{m}} / \mathrm{Fv}_{\mathrm{l}}\right)$. The log transformation was used to normalize the distribution of the ratios. Paired samples $t$-tests were performed to compare all parameters $\left(\mathrm{Fv}_{\mathrm{t}}, \mathrm{FB}, \mathrm{A}_{\mathrm{f}}, \mathrm{P}_{\mathrm{av}}\right.$, and $\left.\mathrm{P}_{\max }\right)$ before and after trimming, separately for the fore and hind limbs (SPSS). The force and pressure data of the left and right limbs were considered as independent data. After inspection, we learned that the left-right differences in the used parameters and in the pressure distribution patterns were generally as large as the differences between corresponding limbs of different animals. Moreover, previous work showed significant differences between left and right feet concerning this type of kinetic data (Van der Tol et al., 2003). The $t$ tests were considered significant at $P<0.05$.

\section{RESULTS}

\section{General}

The claw examinations during the trimmings revealed that the claws were only subclinically affected by interdigital dermatitis. Based on a scale from 0 to 3 described by Peterse (1980), the cows had an average score of 1.4, signifying minor superficial horn defects in the axial part of the bulb. Because the previous trimmings were performed 5 mo before the experiment, no excessive overgrowth was present. Moreover, there were no clinical signs of any claw disorders. Therefore, it can be surmised that our treatment is comparable with that of routine preventive trimming 2 to 3 times a year.

Because the animals were standing still during the measurements, the pressure distribution was relatively stable, as previously described (Van der Tol et al., 2002). Therefore, the 1000 recorded frames of one trial were averaged and plotted in a single pressure image, a typical example of which is shown in Figure 1. Evidenced by their more yellow and red appearances, the parts of the weight-bearing contact area to which the highest pressures were exerted were the bulb areas of both the lateral and the medial claws the forelimbs, the bulb area of the lateral claw at the hind limbs, and the anterior part of the sole of the medial claw.

The difference between the pre- and posttrimming measurements was difficult to analyze qualitatively. One of the reasons was that, between pictures of different measurements, the colors represent different pressures. At first sight, however, it appeared that after trimming the contact area at the hind limbs was increased and, thus, the average pressure decreased.

\section{Vertical GRF}

On average, the animals put 1976 and $2321 \mathrm{~N}$ on each forelimb, before and after trimming, respectively. For the hind limb, the corresponding values were 1406 and $1940 \mathrm{~N}$. The differences before and after trimming caused by a different posture when standing still were not statistically significant. On average, a forelimb carried $31.1 \%$ of the BW, and a hind limb carried $24.3 \%$ of the BW. The differences were not due to weight changes of the cows, but to random variations in the weight exerted to one limb because of variations in weight distribution over the 4 limbs. It should be realized that these values are the result of subsequent, not simultaneous, measurements of the 4 limbs and, therefore, do not necessarily sum up to a $100 \% \mathrm{BW}$.

The FB between the medial and lateral claw was expressed as the log ratio $\left(\mathrm{Fv}_{\mathrm{m}} / \mathrm{Fv}_{\mathrm{l}}\right)$. Figure 2 shows that the ratios are negative, indicating heavier loading 
a)

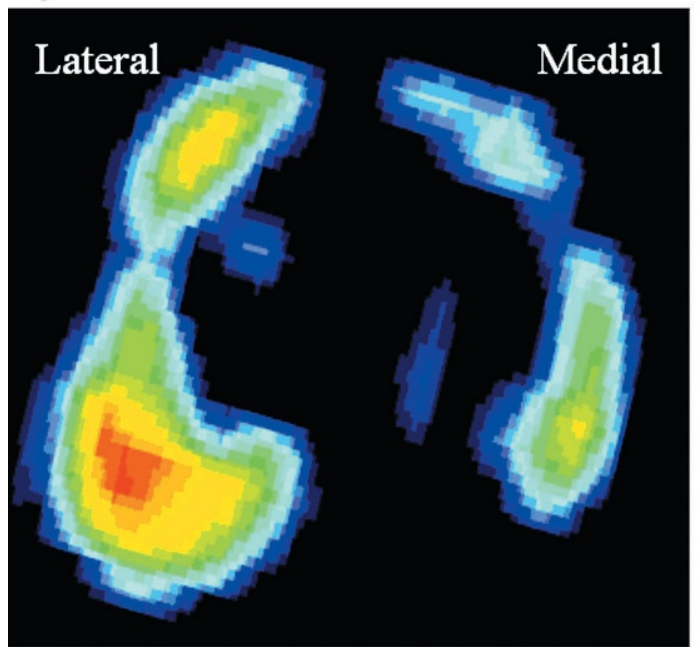

b)

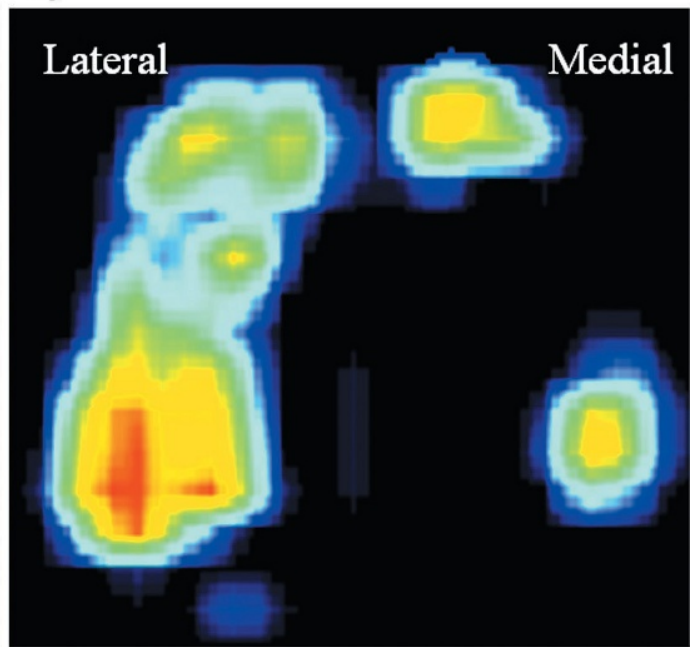

Figure 1. Examples of the pressure distribution at the left hind limb of the same cow a) before and b) after trimming.

of the lateral claw. The forefeet were not significantly different between the pre- and posttrimming measurements. Although in the hind limbs after trimming, the $\log$ ratio $\left(\mathrm{Fv}_{\mathrm{m}} / \mathrm{Fv}_{\mathrm{l}}\right)$ increased significantly from -0.55 to $-0.37(P<0.05)$; the force distribution remained unequal. Broadly speaking, before trimming, $80 \%$ of the total force is taken up by the lateral claw, and $20 \%$ is taken up by the medial claw; after trimming, this becomes 70 and $30 \%$ respectively.

\section{Claw Floor Contact Area}

The contact area of the hind feet was significantly affected by trimming. As can be seen in Figure 3, the contact area of the hind feet increased from 27.5 to 40.0

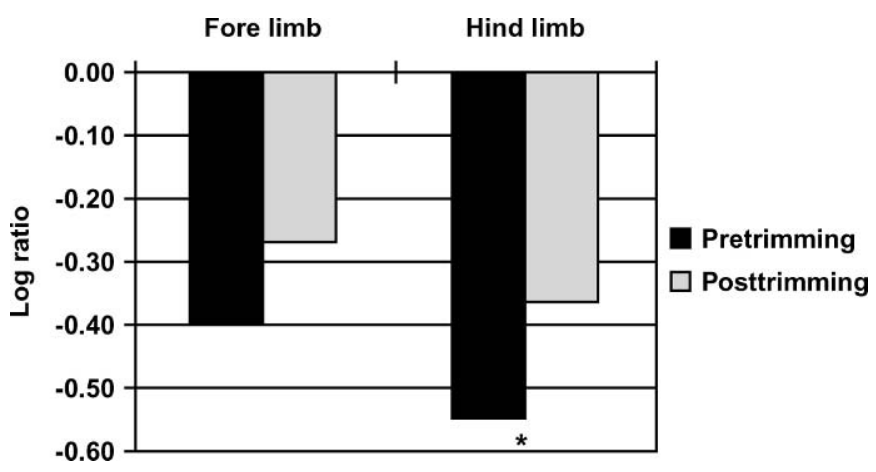

Figure 2. The log ratio $\left(\mathrm{Fv}_{\mathrm{m}} / \mathrm{Fv}_{\mathrm{l}}\right)$ of the distribution of the vertical ground reaction force between the lateral and medial claw before and after trimming for the fore and hind limbs. A ratio of 0 means an equal distribution of vertical force; negative values indicate a higher vertical force on the lateral claw. $* P<0.05$. $\mathrm{cm}^{2}(+45 \%)$ after trimming $(P<0.05)$, and the contact area of the untrimmed forefeet did not change significantly over time $\left(35\right.$ to $\left.38 \mathrm{~cm}^{2}\right)$.

\section{Average and Maximum Pressures}

Before and after trimming, the average pressures at the contact areas of the forefeet were about $60 \mathrm{~N} / \mathrm{cm}^{2}$ and at the hind feet were about $50 \mathrm{~N} / \mathrm{cm}^{2}$. The maximum pressures were, respectively, 124 and $89 \mathrm{~N} / \mathrm{cm}^{2}$. However, in the present experiment, on average, cows put more weight on their limbs after trimming. For an unbiased comparison, the pressure data must be corrected for the amount of weight exerted to the limb. In Figure $4 \mathrm{a}$, it can be seen that after trimming, the corrected average pressure did not change significantly at the forelimbs, although it significantly decreased from 0.35 to $0.24 \mathrm{~N} / \mathrm{cm}^{2}$ per $\mathrm{kg}(-30 \%)$ at the hind limbs. In Figure 4b, it is shown that the corrected maximum

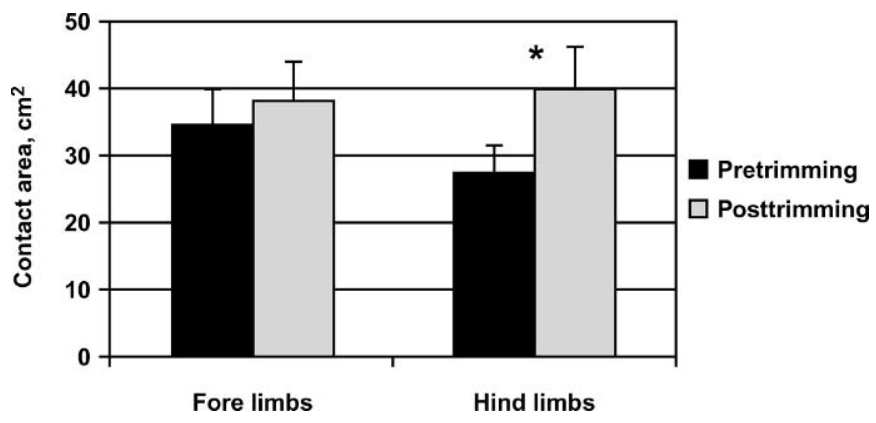

Figure 3. Size of the contact area of the foot (Af) before and after trimming. $* P<0.05$. 
a)

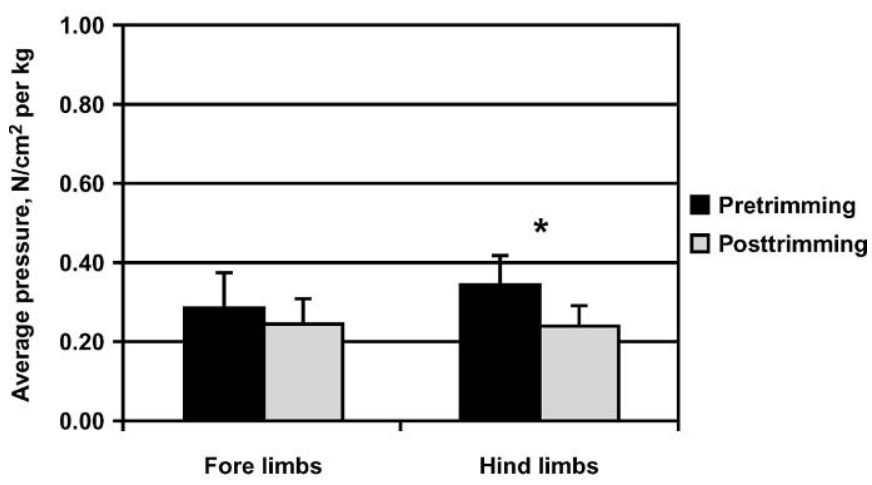

b)

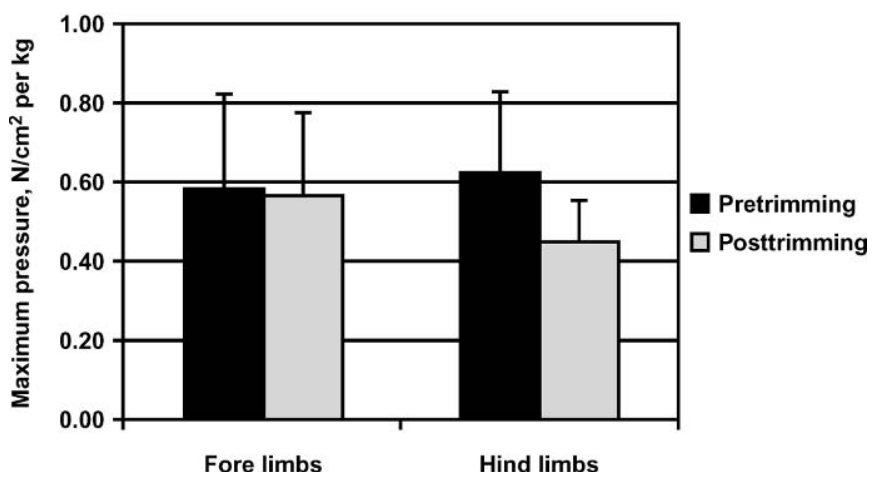

Figure 4. Corrected average (a) and maximum (b) pressure at the contact area of the bovine foot before and after trimming. The correction was performed by dividing the pressure by the weight exerted to the limb as determined by the force plate recordings. As a result of this procedure, the pressure data are expressed in $\mathrm{N} / \mathrm{cm}^{2}$ per kg. $* P<0.05$.

pressure at the hind feet decreases somewhat after trimming; however, this effect was not statistically significant. The maximum pressures remain roughly twice as high as the average pressures, suggesting that trimming does not help to make smooth the pressure distribution.

\section{DISCUSSION}

The forelimbs that were not trimmed did not show any statistically significant differences between the 2 measurements, separated 2 wk in time. This result suggested that the measurements were sufficiently repeatable, and the differences found in the hind limb were due to preventive trimming. Although not statistically significant, the animals put more weight on the hind limbs when measured after preventive trimming. This random effect could lead to the erroneous conclusion that trimming causes an increase in force and pressures. An adjustment is necessary to allow an unbiased comparison of the data before and after trimming. In human biomechanical studies, a normal procedure is to adjust these types of data for the BW of each individual subject. In quadruple body support, this is more difficult, as the cows put a variable portion of their BW on the measured limb. Therefore, the data were adjusted for the amount of weight exerted to the limb, thereby making the pressure data independent of the loading itself. Therefore an objective comparison between and within cows became possible.

\section{Biomechanical Goals of the Dutch Trimming Method}

The first goal of preventive trimming is an improvement in the balance of the foot. Toussaint-Raven et al. (1985) stated that an equal contribution of the medial and lateral claws is needed to support the limbs. However, the question is whether an equal force contribution is the normal condition. In this work and in other studies, an equal contribution was never found. Alsleben et al. (2002) found an increase in relative load on the lateral claw with increasing age in GermanBrown cows. For adult cows of the larger HolsteinFriesian race, results from Ossent et al. (1987) and from this study (before and after trimming) showed an even larger discrepancy in weight bearing. Hence, asymmetry may develop as a result of increased weight, age, or both.

The second desired effect of preventive trimming is to reduce pressure by distribution of the force exerted by the limb over a larger contact area. Trimming led to an increase of the contact area of $45 \%$ and a concomitant decrease of the average pressure by $30 \%$. It is often assumed that trimming also relieves the claw from high maximum pressures. Although, the data suggest such a decrease, this effect was not statistically significant.

When the foot is trimmed, most horn is removed at the lateral claw to match the height of the sole surface of the medial counterpart as closely as possible (Toussaint-Raven et al., 1985; Greenough and Weaver, 1997). Consequently, the wall, the morphologically better candidate for weight bearing, is removed as well. The Dutch method of trimming is supposed to increase the claw angle to induce a forward shift in weight bearing, particularly in claws with overgrown toes (Toussaint-Raven, 1985). The data are not analyzed with regard to a shift in the center of pressure, as this center cannot be related to a stable reference position relative to the contact area of the claw because the area itself has undergone changes caused by trimming. Previous work shows that $2 \mathrm{wk}$ (van der Tol et al., 2002) and $3 \mathrm{wk}$ (Distl et al., 1990) after trimming, the main weight and the highest pressures are exerted to the bulb area of the 
lateral hind claw. Hence, there is little evidence for a forward weight shift in regularly trimmed animals with non-overgrown claws. Despite trimming, the weight of the animal is still transmitted to the caudal part of the claw and underlying tissues (Mair et al., 1988; Distl et al., 1990; van der Tol et al., 2002). Therefore, it is tempting to assume that the current way of trimming (e.g., the Dutch method) does not provide sufficient relief of the caudal pressure concentration. Such a pressure concentration might lead to an overproduction of horn at this location or to haematoma or horn damage (van der Tol et al., 2002 and 2003).

\section{Functional Weight Bearing}

Biomechanical experiments lead Toussaint-Raven (1973) to postulate that the weight carried ideally by a limb should be equally distributed between the medial and lateral claw and should be distributed over a contact area as large as possible. The trimming method that he proposed was meant to achieve this and has been widely adopted since in western European husbandry (O'Callaghan et al., 2001). However, it can be assumed when animals (evolved for thousands of years on soft surfaces) live on natural substrates, the growth and wear of the claw capsule are in equilibrium. Such claws show a more protruding claw wall and less wear of the bulb (Blowey, 1993). In those claws, the wall will accept most of the load on the foot, and the sole and bulb will also participate in load bearing to a degree that depends on the extent to which the foot is sunk into the substrate (Webb and Clark, 1981; Scott, 1988). In the modern dairy housing environment (not a natural habitat), the claw capsule is worn flat because of the current trimming practice and/or the increased abrasion by rough concrete floors (Murphy and Hannan, 1987). The balance in weight bearing of the claw capsule might have shifted from the wall to the sole or bulb area.

A flat contact area should lead to loading of wall, sole, and bulb more in proportion to their exposed bearing surface. However, in such a claw, it appears that the highest pressures are often located at the bulb area during standing and walking (Mair et al., 1988; Distl et al., 1990; van der Tol et al., 2002, 2003). The high pressures at the bulb are not favorable, as its horn is the softest of the claw capsule (Baggot et al., 1988; Zöscher, 2000). Previous work has shown that this horn might experience in vivo pressures relatively close to the compressive breaking strength (van der Tol et al., 2003). Consequently, the risk of horn fractures is highest at the bulb, and a fractured bulb horn might be seen as a first step toward heel horn erosion, claw disorders, or both.
Therefore, biomechanical research should be seeking to provide the cows with such a foot-floor interaction that they will be able to stand and walk naturally with morphological, functional claws. Whether this will be attained by better flooring conditions or an improved method of trimming is still part of discussion.

It should be stressed, however, that this study has only dealt with a single aspect of the Dutch trimming method. Before more definitive conclusions can be drawn, critical studies are needed on all aspects of trimming, in particular the effect of trimming on overgrown or neglected claws. Furthermore, it is possible that a protruding wall will become subjected to bending moments, exerted by horizontal or vertical GRF. Although there is no clear and epidemiological evidence that this happens (Benz, 2002; Manske et al., 2002), such moments may bend the wall horn and put its connection with the sole (the so-called white line) under tensile stress. Nevertheless, in case of routine preventive claw trimming, the results suggest that force balance should not be the main focus, but it could be beneficial to aspire to a decrease of local maximum pressures at the contact area in such a way that the strongest parts of the claw capsule (i.e., the wall) will be subjected to the highest pressures.

\section{REFERENCES}

Alsleben, B., A. Russke, J. Wrede, H. Hamann, and O. Distl. 2002. Measurements of the pressure distribution of the claws of German Brown cattle during the first two years of life. Tierartzliche Umschau 57:657-666.

Baggott, D. G., K. J. Bunch, and K. R. Gill. 1988. Variations in some inorganic components and physical properties of claw keratin associated with claw disease in the British Friesian cow. Br. Vet. J. 144:534-542.

Benz, B. 2002. Elastische Beläge für Betonspaltenböden in Liegeboxenställen. Thesis 394, Hohenheim, Germany.

Blowey, R. 1993. Catttle lameness and hoofcare. Farming Press, Ipswich, UK.

Borsberry, S., D. Logue, R. Laven, C. L. Watson, P. Ossent, and C. Livesey. 1999. Report on lameness workshop (Harper Adams) "Lameness in the dairy cow" Cattle Pract. 7:307-310.

Clarkson, M. J., D. Y. Downham, W. B. Faull, J. W. Hughes, F. J. Manson, J. B. Merrit, R. D. Murray, W. B. Russel, J. E. Sutherst, and W. R. Ward. 1996. Incidence and prevalence of lameness in dairy cattle. Vet. Rec. 138:563-567.

Distl, O., H. Krausslich, A. Mair, C. Spielmann, and W. Diebschlag. 1990. Computer aided analysis of pressure distribution underneath claws of cattle. Dtsch. Tieraertzl. Wochenschr. 97:474-479.

Enting, H., D. Kooij, A. A. Dijkhuizen, R. B. M. Huirne, and E. N. Noordhuizen-Stassen. 1997. Economic losses due to clinical lameness in dairy cattle. Livest. Prod. Sci. 49:259-267.

Esslemont, R. J., and I. Spincer. 1993. The incidence and costs of the diseases in dairy herds. DAISY, Dep. Agric., Univ. Reading, UK, Rep. 2:58.

Gonzalez Sagues, A. 2002. The biomechanics of weight bearing and its significance with lameness. Pages 117-121 in Proc. 12th Int. Symp. Lameness in Ruminants, Orlando, FL.

Greenough, P. R., and A. D. Weaver. 1997. Lameness in Cattle, 3rd ed. W. B. Saunders, PA. 
Hedges, J., R. W. Blowey, A. J. Packington, C. J. O'Callaghan, and L. E. Green. 2001. A longitudinal field trial on the effect of biotin on lameness in dairy cows. J. Dairy Sci. 84:1969-1975.

Mair, A., C. Spielmann, W. Diebschlag, H. Krausslich, F. Graf, and O. Distl. 1988. The measuring of pressure distribution on the soles of the claws of cattle-A fundamental investigation based on a new measuring device. Dtsch. Tieraertzl. Wochenschr. 95:325-328.

Manske, T., J. Hultgren, and C. Bergsten. 2002. The effect of claw trimming on the hoof health of Swedish dairy cattle. Prev. Vet. Med. 54:113-129.

Manson, F. J., and J. D. Leaver. 1989. The effect of concentrate:silage ratio and of hoof trimming on lameness in dairy cattle. Anim. Prod. 49:15-22.

Murphy, P. A., and J. Hannan. 1987. Effects of slatted flooring on claw shape in intensively housed fattening beef cattle. Bovine Pract. 22:133-135.

O’Callaghan, K. A., R. D. Murray, W. R. Ward, and P. J. Cripps. 2001. Questionnaire survey of perceptions of veterinary surgeons and cattle foot trimmers on cattle lameness. [Online]. Available at: http://www.nacft.co.uk/liverpool_survey.htm.

Ossent, P., D. J. Peterse, and H. C. Schamhardt. 1987. Distribution of load between the lateral and the medial hoof of the bovine hind limb. J. Vet. Med. A 34:296-300.

Peterse, D. J. 1980. Judgement of bovine claws by the occurrence of sole lesions. Ph.D. Diss. State Univ., Utrecht, The Netherlands.

Russel, A. M., G. J. Rowlands, S. R. Shaw, and A. D. Weaver. 1982. Survey of lameness in British dairy cattle. Vet. Rec. 111:155-160.

Scott, G. B. 1988. Studies of the gait of Friesian heifer cattle. Vet. Rec. 123:245-248.

Shearer, J. K., and S. R. van Amstel. 2001. Functional and corrective claw trimming. Vet. Clin. North. Am. Food Anim. Pract. 17:53-72.
Somers, J. G. C. J., K. Frankena, E. N. Noordhuizen-Stassen, and J. H. M. Metz. 2003. Prevalence of claw disorders in Dutch dairy cows exposed to several floor systems. J. Dairy Sci. 86:2082-2093.

Toussaint-Raven, E. 1973. Determination of weight bearing by the cows foot. Dutch J. Vet. Med. 5:1237-1243.

Toussaint-Raven, E. 1985. The principles of claw trimming. Symp. bovine lameness and orthopedics. Vet. Clinics of North Am. Food Anim. Pract. 1:93-107.

Toussaint-Raven, E., R. T. Halstra, and D. J. Peterse. 1985. Cattle Foot Care and Claw Trimming. Farming Press, Ipswich, UK.

Van Amstel, S. R. 2002. Claw trimming: An adaptation to the Dutch method. Pages 127-130 in Proc. 12th Int. Symp. Lameness in Ruminants, Orlando, FL.

Van der Tol, P. P. J., J. H. M. Metz, E. N. Noordhuizen-Stassen, W. Back, C. R. Braam, and W. A. Weijs. 2002. The pressure distribution under the bovine claw during square standing on a flat substrate. J. Dairy Sci. 85:1476-1481.

Van der Tol, P. P. J., J. H. M. Metz, E. N. Noordhuizen-Stassen, W. Back, C. R. Braam, and W. A. Weijs. 2003. The vertical ground reaction force and the pressure distribution on the claws of dairy cows while walking on a flat substrate. J. Dairy Sci. 86:2875-2883.

Vermunt, J. J., and P. R. Greenough. 1995. Structural characteristics of the bovine claw: Horn growth and wear, horn hardness and claw conformation. Br. Vet. J. 151:157-180.

Webb N. G., and M. Clark. 1981. Livestock foot-floor interactions measured by force and pressure plate. Farm Building Progress 66:23-36.

Whay, H. R., A. E. Waterman, and J. F. Webster. 1997. Associations between locomotion, claw lesions and nociceptive threshold in dairy heifers during the peri-partum period. Vet. J. 154:155-161.

Zöscher, M. 2000. Mechanische Eigenschaften von Klauenhorn beim Rind: Elastizitätsmodul, Kugeleindruckhärte und Shore- DHärte in Abhängigkeit vom Trockensubstanzgehalt und der position der Klaue. Thesis, Veterinärmedizinischen Universität, Wien. 